\title{
Conflict of interest and the credibility of medical journals
}

\author{
GIOVANNI A. FAVA
}

Editor, Psychotherapy and Psychosomatics

The issue of conflict of interest is getting more and more important for medical journals (Alpert, 2002; Anonymous, 2002; van Kolfschooten, 2002). It undermines the credibility of papers which are submitted, their review process, and even the editorial decisions about acceptance or rejection.

The notion of conflict of interest is widely used but may entail different meanings. Margolis (1979) distinguishes between conflicting interests and conflicts of interest. The former occur in any situation where competing considerations are presumed to be legitimate. Conflicts of interest, on the other hand, are characterized by individual occupying dual roles, which should not be performed simultaneously. Because of the potential for abuse, performing both roles at the same time is considered to be inappropriate. Which roles? For instance, being a researcher and holding a financial interest in an area related to the research one is involved in. Despite the growing interest, however, the current debate on conflict of interest in medicine seems to fail to grasp its basic components. Such components emerge from a proper historical consideration of the debate.

The first investigation suggesting the danger of conflict of interest in medicine appeared in the Annals of Internal Medicine in 1992. Wilkes et al. (1992) assessed the accuracy of scientific data presented in the pharmaceutical advertisements of 10 leading medical journals.

Address for correspondence: Professor G.A. Fava, Department of Psychology, University of Bologna, Viale Berti Pichat 5, 40127 Bologna (Italy).

Fax: +39-051-243.086

E-mail: fava@psibo.unibo.it

Declaration of Interest: no conflict of interest.
Each full-page pharmaceutical advertisement was sent to 3 reviewers: In $30 \%$ of the cases, 2 or more reviewers disagreed with the advertisers' claim that the drug was the 'drug of choice'. In $44 \%$ of cases, the reviewers felt that the advertisement would lead to improper prescribing if a physician had no other information about the drug other than that contained in the advertisements. The potential adverse consequences of misleading advertisements are obvious: increased health care costs when physicians have been persuaded to prescribe expensive new drugs over equally effective lower-cost drugs or nonpharmaceutical treatments (e.g. psychotherapy), or needless harm or even death because physicians have been persuaded to prescribe products for uses for which they have not been adequately tested (Kessler, 1992).

The implications of the study by Wilkes et al. (1992), however, were largely ignored. Denial also characterized the reactions to a second landmark study on conflict of interest. Krimsky et al. (1998) analyzed 789 articles written by authors from Massachusetts universities publishing in leading scientific journals in 1992. In 1 out of 3 cases, at least 1 author had a vested interest in research. Krimsky et al. (1998) took a very conservative stand as to what constitutes a financial conflict of interest: owing a patent directly related to the published work; being a major stockholder or executive in a company with commercial interests tied to the research, or serving on the board of directors of such a company. The percentage of cases of conflict of interest would have greatly increased if consultancies and honoraria had been taken into account. The study clearly showed the extent of corporate presence in scientific publishing. These results, however, as it happened with the study by Wilkes et al. (1992), were systematically downplayed by the scientific community, as exemplified by the response of Nature to them. 
In the nineties, an impressive body of facts pointed to the danger of conflict of interest in medicine. It is worth mentioning that such disclosure often took place in the media, instead of coming from the scientific community. For instance, Zalewski (1997) illustrates an impressive list of examples where the issue of conflict of interest was associated with important scientific and clinical issues. At times, conflict of interest may undermine the credibility of scientific data, such as in the scandal over a study on a heart attack medication (TPA) published in the Journal of the American Medical Association, when a reporter from Newsday revealed that at least 13 researchers were long-term stockholders of the company manufacturing the drug.

Other data, in the mean time, have been published. Glassman et al. (1999) investigated whether revenues generated from pharmaceutical advertisements in medical journals create potential conflicts of interest for nonprofit physician organizations that own those journal. They found that financial conflicts of interest were substantial, and some prestigious medical organizations, such as those underlying the Journal of the American Medical Association and the New England Journal of Medicine, could be viewed as beholden to the drug industry. In an accompanying editorial, Lexchin (1999) reported on the growing concern about the relationship between the World Health Organization (WHO) and the pharmaceutical industry. WHO recently issued a set of guidelines for the diagnosis and management of essential hypertension in conjunction with the International Society of Hypertension. A letter signed by close to 900 physicians and scientists pointed out that the guidelines ignored ground rules of clinical assessment and placed an excessive weight on trials funded by the pharmaceutical companies. This casts serious doubts on the WHO, which has been accepting temporary substitutes of personnel from the pharmaceutical industry. As it has been pointed out concerning the diagnosis of depression and the use of antidepressant drugs, the game is clear: to get as close as possible to universal consumption of a drug, either by stretching its indications (e.g. to include demoralization) or by encouraging its preventive use (Fava, 2002).

A recent review (Wazama, 2000) has outlined how attending sponsored CME events and accepting funding for travel or lodging for educational symposia were associated with an increased prescription rate of the sponsor's medication. Attending presentations given by pharmaceutical representative speakers was also associated with nonrational prescribing. Wilkes (2000) commented on the consequences of the interactions: 'Physicians take gifts form drug companies and then spend patients' money to help make the same pharmaceutical industry the most profitable in the world. They recruit 'research' subjects without advising them of the personal financial gain that accrues to them (...). All these behaviors are directly opposed to what patients and society expect from us in return for the privileges that have been bestowed', p. 7. And, as the subtitle of the editorial indicates, when trust goes, so does the healing power of physicians.

The issue is whether specific episodes that emerge are the unavoidable drawbacks of a scientific system that functions in a substantially independent way, or whether they are simply the tip of the iceberg. What iceberg? Corporate interests which result in self-selecting academic oligarchies (special interest groups) that influence clinical and scientific information (Fava, 2001). These special interest groups exert their influence in many ways, but with the primary target of propaganda (Chomsky \& Barsamian, 2001). This may be targeted to both the clinicians and the general public.

Journals' supplements to support the new release of a drug are a common practice; the fact that their articles are rarely peer reviewed and of lower scientific standard than those that are published in the regular issues of the journals, and that authors often received a fee for them, is not always appreciated and may mislead readers. Apparently, it is also possible to buy editorials (Brennan, 1994), and placing misleading advertisements seems to be the rule. But this is only the most obvious tip of the iceberg. Members of corporate-driven special interest groups, in virtue of their financial power and close ties with other members of the group, often get leading roles in editing medical journals and in advising nonprofit research organizations. They act as reviewers and consultants, with the task of systematically preventing dissemination of data which may be in conflict with their special interests. The fact that a large body of important research does not get published is increasingly acknowledged (Gilbody \& Song, 2000) and undermines the so-called evidencebased medicine; not sufficiently acknowledged, however, are the difficulties that authors who are swimming against the tide encounter in getting their findings published. The most powerful way corporate driven academic oligarchies have to display their power and influence is through meetings and symposia, particularly in professional societies meetings. Elsewhere (Fava, 1995), I have described the 'prodigal experts' who characterize such practice.

The danger then becomes obvious. As Krimsky et al. (1998) remarked, the scientific community is draining itself of a reservoir of disinterested experts who can be called upon to advise government policy markers on the 
safety and efficacy of treatments, on the hazards of chemicals and on the safety of technology. These experts may find increasing difficulties in getting support from research grant agencies and in obtaining appropriate visibility at meetings and in journals. It is not that disinterested experts are extinct, as the agencies would like people to believe. It is that they are marginalized by the gatekeepers of corporate interest within public institutions.

\section{ALTERNATIVE SOLUTIONS}

A substantial problem in developing effective strategies toward a better control of the problem of conflict of interest in clinical medicine lies in the lack of its identification with the more general problems related to the growing power of transnational corporations. Only in January of 2001 Nature (Anonymous, 2001) acknowledged the similarities between attempts to control the university - industrial complex and the post-Seattle movement. The strategies adopted by transnational corporation to influence the media and get rid of any obstacles at the level of national countries (Chomsky, 1999) are the ones which take place in clinical medicine. Unfortunately, most of the journal editors and academic physicians still believe that the problem can be addressed simply within their journals or universities. In particular, editors of journals with substantial advertisements fake a control over their medical information they no longer have.

Attempts to limit undue influences in clinical medicine have emphasized the importance of disclosure policies. Such policies are now endorsed by an increasing number of journals. Further, disclosure of conflict of interest is now requested at several association meetings, mainly in North America. This is a minimal requirement for scientific credibility.

But it is simply not performed. Krimsky (2001) found, in a study involving over 60,000 articles in journals, that conflict of interest was reported in less than $1 \%$ of articles, despite the policies concerned with conflict of interest in the journals. This simply means that even the first step of disclosure is not endorsed. The recent, stringent instructions of the JAMA on reporting financial conflicts of interest and relationships between investigators and research sponsors (De Angelis et al., 2001), can also be read as a recognition of this failure. Further, it is curious how disclosure is not endorsed to its full consequences. In some journals, all reviewers (whether members of the editorial board or not) should disclose any potential conflict of interest in their comments to the editor. But how many journals share this policy? It is certainly more reas- suring to discuss blind or nonblind reviews. And what about the editors? I believe that the time has come for editors to disclose any potential conflict of interest that has occurred in the previous year.

If disclosure is a first and essential step towards dealing with conflict of interest contamination in science, not even the most optimistic people would believe it may be sufficient, even in its most complete form. Something else needs to be developed.

An effective control of the issue of conflict of interest - in addition to disclosure policies - may results from the following converging developments.

1) Within each specific field, one has no difficulties in recognizing special interest groups. They are so powerful, they run the field. What can one do? Not unlike the alternative consumer, at an individual level, one can also decline participation in specific meetings or society events (Fava, 1992). Members attending a meeting of their association should be able to rate the quality and the influence of the pharmaceutical industry with appropriate evaluation forms and to manifest their dissent (electronic mail is a powerful instrument for it).

2) It is also important for independent thinkers and physicians not to be isolated. The site www.nofreelunch.org is an example of this trend of resistance. Journals such as Psychotherapy and Psychosomatics, the Western Journal of Medicine and the International Journal of Risk and Safety in Medicine are leading forces in fostering independent thinking. It is of the utmost importance that critical ideas may find their way and not be confined to only a few researchers. Nonsponsored meetings should be pursued actively. Groups of independent physicians may also start boycotting specific corporations or associations, if this was found to be the case. For instance, a company filed a lawsuit against the study's lead investigators and their universities for publishing the results of a study showing that a HIV-1 vaccine was no better than placebo (Anonymous, 2000). This is perfectly in line with the general strategies of the transnational corporations (Chomsky, 1999). One could envision boycotting all products of that company, in support of those brave investigators, as consumers have long performed with non-medical products.

3) The development of specific policies for integrity in science (as Harvard Medical School did in 1994) by universities or granting agencies is also important.

4) The creation of independent review bodies (within each field) for examining the issues concerned with conflicts of interest would be another important step. Such bodies might provide peer support to struggling 
editors or authors, well beyond the generic, if not ridiculous, encouragement to register unpublished research (Smith \& Roberts, 1997).

5) Consumers' associations have not fully realized the importance of addressing the issue of conflict of interest in the news media. A notable exception is represented by the brave battle of a British consumers' association for the recognition of withdrawal reactions following benzodiazepines (Medawar, 1992) and use of second-generation antidepressants (Medawar, 1997). In a recent study (Moynihan et al., 2000), news media stories about medication were found to frequently include inadequate or incomplete information about the risks of the drugs as well as the financial ties between study groups or experts and pharmaceutical manufacturers. The civil society should realize that public research money is often invested for the benefits of the special interest groups instead of to address key public health issues. The role of the public's advice on general strategies of granting agencies needs to be increased.

6) The making of this counter culture in corporate-driven clinical medicine cannot be exempt from a broad, biopsychosocial, multifactorial consideration of the balance between health and disease (Ryff \& Singer, 2000; Fava \& Sonino, 2000). Once again, psychosomatic medicine unfolds its alternative potential. An increasing number of physicians has started wondering why the cures that molecular biology promised have not appeared and to wonder whether the laboratory is the best place to pursue them. Patients continue to suffer from cancer, heart disease and depression. And the work that has actually changed how doctors treat the sick has come mostly from researchers who focus on patients and on the environmental correlates of illness. This paves the way for a renewed effort to integrate biological, psychological and social factors in a holistic view of the balance between health and disease. Without this psychosomatic consideration, all efforts to limiting the propaganda skillfully orchestrated by special interest groups to promote corporate products is likely to fail.

\section{REFERENCES}

Alpert J.S. (2002). Conflict of interest. Science, money, and health. Archives of Internal Medicine 162, 635-637.

Anonymous. (2000). Company sought to block paper's publication. Lancet 356, 1659.

Anonymous. (2001). Is the university - industrial complex out of control? Nature 409, 119.
Anonymous (2002). How just tainted has medicine become? Lancet $359,1157$.

Brennan T.A. (1994). Buying editorials. New England Journal of Medicine 331, 673-675.

Chomsky N. (1999). Profit over People. Neoliberalism and Global Order. Seven Stories Press: New York.

Chomsky N. \& Barsamian D. (2001). Propaganda and the Public Mind. South End Press: Cambridge, MA.

De Angelis C.D., Fontanarosa P.B. \& Flanagin A. (2001). Reporting financial conflicts of interest and relationships between investigators and research sponsors. Journal of the American Medical Association 286, 89-91.

Fava G.A. (1992). Bartleby, the scrivener. Psychotherapy and Psychosomatics 57, 81-82.

Fava G.A. (1995). Holding on: depression, sensitization by antidepressant drugs, and the prodigal experts. Psychotherapy and Psychosomatics 64, 57-61.

Fava G.A. (2001). Conflict of interest and special interest groups. Psychotherapy and Psychosomatics 70, 1-5.

Fava G.A. (2002). Long-term treatment with antidepressant drugs: the spectacular achievements of propaganda. Psychotherapy and Psychosomatics 71, 127-132.

Fava G.A. \& Sonino N. (2000). Psychosomatic medicine: emerging trends and perspectives. Psychotherapy and Psychosomatics 69, 184-197.

Gilbody S.M. \& Song F. (2000). Publication bias and the integrity of psychiatry research. Psychological Medicine 30, 253-258.

Glassman P.A., Hunter Hayes J. \& Nakamura T. (1999). Pharmacological advertising revenue and physician organizations: How much is too much? Western Journal of Medicine 171, 234-235.

Kessler D.A. (1992). Addressing the problem of misleading advertising. Annals of Internal Medicine 116, 950-951.

Krimsky S. (2001). Journal policies on conflict of interest: if this is the therapy, what's the disease? Psychotherapy and Psychosomatics $70,115-117$

Krimsky S., Rothenberg L.S., Stott P. \& Kyle G. (1998). Scientific journals and their authors' financial interests: A pilot study. Psychotherapy and Psychosomatics 67, 194-201.

Lexchin J. (1999). Don't bite the hand that feeds you. Western Journal of Medicine 171, 238-239.

Margolis J. (1979). Conflict of interest and conflicting interests. In Ethical Theory and Business (ed. T.L. Beauchamp and N.E. Bowie), pp 361-372. Englewood Cliffs: Prentice-Hall.

Medawar C. (1992). Power and Dependence. Social Audit: London.

Medawar C. (1997). The antidepressant web. International Journal of Risk and Safety in Medicine 10, 75-126.

Moynihan R., Bero L., Ross-Degnan D., Henry D., Lee K., Watkins J., Mah C. \& Sounerar S.B. (2000). Coverage by the news media of the benefits and risks of medications. New England Journal of Medicine 342, 1642-1650.

Ryff C.D. \& Singer B. (2000). Biopsychosocial challenges of the new millenium. Psychotherapy and Psychosomatics 69, 170-177.

Smith R. \& Roberts I. (1997). An amnesty for unpublished trials. British Medical Journal 315, 622.

Van Kolfschooten F. (2002). Can you believe what you read? Nature $416,360-363$.

Wazana A. (2000). Physicians and the pharmaceutical industry. Is a gift ever just a gift? Journal of the American Medical Association 283, 373-380.

Wilkes MS. (2000). Conflict, what conflict? When trust goes, so does the healing power of physicians. Western Journal of Medicine 172 , 6-8.

Wilkes M.S., Doblin B.H. \& Shapiro M.F. (1992). Pharmaceutical advertisement in leading medical journals: experts' assessments. Annals of Internal Medicine 116, 912-919.

Zalewski D. (1997). Ties that bind: Do corporate dollars strangle scientific research? Linguafranca 7, 51-59. 